\title{
Atrial fibrillation and cognitive function: case-control study
}

\author{
Janice E O'Connell, Christopher S Gray, Joyce M French, Ian H Robertson
}

School of Clinical Medical Sciences, University of Newcastle upon Tyne, Department of Medicine for the Elderly, Sunderland Royal Hospital, Kayll

Road, Sunderland

SR4 7TP, UK

J E O'Connell

C S Gray

Department of

Statistics, University of

Newcastle upon Tyne,

UK

J M French

MRC Applied

Psychology Unit, Rehabilitation

Research Group,

Addenbrooke's

Hospital, Cambridge

CB2 2QQ, UK

I H Robertson

Correspondence to: Dr JE O'Connell,

Department of Medicine for the Elderly, Sunderland

Royal Hospital, Kayll Road,

Sunderland SR4 7TP, UK.

Received 13 June 1997 and in final revised form 3

February 1997

Accepted 3 February 1997

\begin{abstract}
Atrial fibrillation is an important and independent risk factor for cerebrovascular disease and vascular dementia. There is increasing evidence that atrial fibrillation is associated with an increased risk of asymptomatic or silent cerebral infarction and as a result may confer an increased risk of progressive cognitive impairment on a person. In this study we sought to determine whether this hypothesis could be explored in a prospective case controlled design. Twenty seven patients with non-valvular atrial fibrillation (NVAF) and no history of stroke, transient ischaemic attack, dementia, and thyrotoxicosis were compared with 54 age and sex matched controls in sinus rhythm. All cases underwent clinical examination, ECG, and psychological assessment using a battery of nine neuropsychological tests. Between group analysis and a comparison of mean test scores of paired controls with cases were undertaken. The presence of atrial fibrillation was consistently associated with poorer performances on all the subtests of the neuropsychological battery. There was no association between duration of atrial fibrillation and performance. These results provide evidence to justify further examination of the hypothesis in a larger prospective study to determine whether antithrombotic therapy may protect against cognitive decline in patients at maximal risk of silent cerebral ischaemia and associated cognitive decline.

(F Neurol Neurosurg Psychiatry 1998;65:386-389)
\end{abstract}

Keywords: cognitive function; atrial fibrillation; cerebral ischaemia

Cerebrovascular disease is the most important potentially preventable form of dementia and in very elderly people vascular dementia may account for almost half of all cases. ${ }^{1}$ Atrial fibrillation is well recognised as an important and independent risk factor for cerebrovascular disease at all ages. ${ }^{2}$ The prevalence of atrial fibrillation rises with increasing age with estimates of $<4 \%$ in those aged $<70$ years up to $13 \%$ in persons aged $>85$ years. $^{3}$
Most cases of atrial fibrillation are now of non-rheumatic or non-valvar (NVAF) aetiology. ${ }^{4}$ NVAF confers a fivefold increased risk of clinically apparent stroke compared with sinus rhythm. ${ }^{5}$ Studies with CT confirm that asymptomatic or silent cerebral infarction occurs more commonly in the presence of NVAF than sinus rhythm. ${ }^{67}$ Recent evidence from the European Atrial Fibrillation trial (aspirin/anticoagulants in secondary stroke prevention in patients with NVAF and transient ischaemic attack/stroke) supports these findings, with CT evidence of previous silent stroke being present in $14 \%$ of patients. Silent cerebral infarction was not associated with the nature (chronic/paroxysmal) or duration of atrial fibrillation. ${ }^{8}$

On the basis of current knowledge, the only major cause of dementia that may be preventable is the syndrome of multi-infarct dementia. It is recognised that patients with multiple small cerebral infarcts are at risk of progressive cognitive impairment, both manifest and subclinical. ${ }^{910}$

We have previously hypothesised that people with NVAF are at increased risk of progressive cognitive impairment as a result of silent cerebral infarction. ${ }^{11}$ In this study we sought to determine (1) whether this hypothesis could be explored in a prospective case controlled study design and (2) to determine which subtests in the selected psychometric test battery were most applicable to the study population.

\section{Methods}

This was a prospective community based study undertaken in a single fund holding general practice in Central Gateshead, Tyne and Wear, England. A total of 1421 out of 9162 patients were aged over 65 years. Patients with atrial fibrillation were identified from computerised practice records and drug history searches as previously described. ${ }^{4}$ NVAF was defined as ECG established atrial fibrillation in the absence of a history or clinical evidence of valvular heart disease (all causes) at the time of assessment. Exclusion criteria were: history of stroke, transient ischaemic attack, dementia or thyrotoxicosis; permanent cardiac pacemaker; and long term anticoagulant therapy. Controls were identified as the next patient on the general practitioner register in sinus rhythm and matched for age (within 1 year) and sex. Data 
Table 1 Compliance with neuropsychological test battery for all subjects (NVAF cases and controls), including comparison between sexes

\begin{tabular}{llll}
\hline & $\begin{array}{l}\text { All subjects } \\
(n=81)\end{array}$ & $\begin{array}{l}\text { Men } \\
(n=48)\end{array}$ & $\begin{array}{l}\text { Women } \\
(n=33)\end{array}$ \\
\hline $\begin{array}{l}\text { Mini mental state } \\
\quad \text { examination }\end{array}$ & 81 & 48 & 33 \\
$\begin{array}{l}\text { National adult reading test } \\
\text { Logical memory test }\end{array}$ & 79 & 47 & 32 \\
Rey figure & 80 & 47 & 33 \\
Digit span & 81 & 48 & 33 \\
PASAT -4 s & 38 & 48 & 33 \\
PASAT -2 s & 22 & 27 & $11^{\star}$ \\
Map search & 80 & 48 & $6^{\star \star}$ \\
Telephone tasks & 77 & 46 & 31 \\
\hline
\end{tabular}

${ }^{\star} \mathrm{p}=0.04 ;{ }^{\star \star} \mathrm{p}=0.13$.

were collected on duration of atrial fibrillation, history of cardiovascular disease, vascular risk factors, and drug treatment. In addition, clinical markers of cardiovascular disease were recorded.

All assessments were carried out in the person's home by one observer (JO'C). All subjects underwent full clinical examination and 12 lead ECG was performed.

Psychological assessment was performed using the following tests: (1) mini mental state examination (MMSE), general cognitive function $^{12}$; (2) national adult reading test (NART), control for premorbid intelligence ${ }^{13}$; (3) Wechsler logical memory test; verbal long term memory ${ }^{14}$; (4) Rey complex figure test, non-verbal memory ${ }^{15} ;(5)$ digit span subtest of the Wechsler adult intelligence scale, short term memory ${ }^{16}$; (6) paced auditory serial addition test (PASAT), speed of information processing and attention ${ }^{17}$; (7) map search subtest of the test of everyday attention, selective attention ${ }^{18-19}$; (8) telephone search task, selective attention ${ }^{18}{ }^{19} ;$ and (9) telephone search dual task, divided attention. ${ }^{18}$

STATISTICAL ANALYSIS

Data were analysed using SPSS for Windows. Between group analysis was undertaken to compare results between patients with NVAF and controls in sinus rhythm. Further analysis involved a comparison of the mean test scores of paired controls with their respective cases.

\section{Results}

SUBJECTS

We identified 91 cases of known atrial fibrillation of whom 27 were eligible for inclusion. Eighty one subjects (48 men) were studied; 27 cases (NVAF; mean age 71.96 (SD 1.45)) and 54 age and sex matched controls (sinus rhythm; 72 (SD 1.02)). There was no significant difference in age between sexes. The groups were equally matched for medical history apart from a history of congestive heart failure which was significantly more common in patients with atrial fibrillation $(\mathrm{p}<0.05)$. Palpitation (awareness of rapid heart beat) was the only symptom significantly more often described by the patients $(p=0.01)$ and there was no difference in symptoms or signs of cardiac failure.

All patients were in atrial fibrillation (established by ECG) at the time of assessment. Most (15) had a history of chronic atrial fibrillation; 12 had previously been diagnosed as paroxysmal. The median known duration of atrial fibrillation was 2 years, range $1-23$ years. Four cases and six controls were taking regular aspirin therapy.

\section{COMPLIANCE WITH THE NEUROPSYCHOLOGICAL} TEST BATTERY

The ability of the study subjects to undertake and complete the test battery is shown in table 1. In all cases the complete test battery was administered in 60 minutes.

\section{NEUROPSYCHOLOGICAL TEST BATTERY}

General cognitive function and intelligence

Performance of cases and controls was compared (1) between groups (Mann-Whitney $U$ test) and (2) between the mean test scores of paired controls with their respective cases (Wilcoxon matched pairs signed rank two

Table 2 Comparison of performance on neuropsychological test battery between NVAF cases and controls in sinus rhythm

\begin{tabular}{|c|c|c|c|c|}
\hline Neuropsychological test & $\begin{array}{l}\text { Mean score } \\
\text { cases }\end{array}$ & $\begin{array}{l}\text { Mean score } \\
\text { controls }\end{array}$ & $\begin{array}{l}\text { Mann- } \\
\text { Whitney U test }\end{array}$ & $\begin{array}{l}\text { Wilcoxon matched } \\
\text { pairs signed rank } 2 \\
\text { tailed p value }\end{array}$ \\
\hline \multicolumn{5}{|l|}{ General cognitive function or IQ: } \\
\hline Mini mental state examination (MMSE) & 26.3 & 27.2 & 0.3 & 0.2 \\
\hline National adult reading test (NART) & 106.5 & 110.3 & 0.07 & 0.1 \\
\hline \multicolumn{5}{|l|}{ Verbal and non-verbal memory: } \\
\hline Logical memory (immediate) & 37.4 & 41.1 & 0.5 & 0.4 \\
\hline Logical memory (delayed) & 38.7 & 49.4 & 0.08 & 0.02 \\
\hline Rey figure (copy) & 30.3 & 31.2 & 0.8 & 0.8 \\
\hline Rey figure (delayed) & 11.1 & 13.0 & 0.2 & 0.2 \\
\hline Digit span subtest & 12.9 & 13.7 & 0.2 & 0.3 \\
\hline \multicolumn{5}{|l|}{ Attention: } \\
\hline \multicolumn{5}{|l|}{ Paced auditory serial addition test: } \\
\hline PASAT $4(\mathrm{~s})$ & 41.9 & 53.8 & 0.005 & 0.02 \\
\hline PASAT 2 (s) & 25.6 & 34.7 & 0.01 & 0.08 \\
\hline \multicolumn{5}{|l|}{ Telephone tasks } \\
\hline Telephone search: (targets (n)) & 18.0 & 17.4 & 0.6 & 0.5 \\
\hline Telephone search: time & 91.1 & 83.04 & 0.3 & 0.3 \\
\hline Dual task decrement & 16.6 & 3.6 & 0.4 & 0.6 \\
\hline Time per target & 5.1 & 5.2 & 0.08 & 0.6 \\
\hline \multicolumn{5}{|l|}{ Map search subtest: } \\
\hline 1 Minute left & 18.5 & 20.5 & 0.4 & 0.4 \\
\hline 1 Minute right & 3.4 & 5.4 & 0.4 & 0.2 \\
\hline 2 Minutes left & 11.5 & 9.4 & 0.06 & 0.2 \\
\hline 2 Minutes right & 9.7 & 13.3 & 0.05 & 0.08 \\
\hline 1 Minute total & 22.0 & 25.8 & 0.2 & 0.09 \\
\hline 2 Minutes total & 21.2 & 22.6 & 0.4 & 0.5 \\
\hline
\end{tabular}


tailed $\mathrm{p}$ ). There was no significant difference between cases and controls for general cognitive function (MMSE) and premorbid intelligence (NART) although controls consistently scored higher than cases (table 2).

\section{Verbal and non-verbal memory}

Cases scored lower than controls for all tests of verbal and non-verbal memory with significance in the between pairs analysis for the delayed logical memory subtest (table 2).

\section{Attention}

When performance on the PASAT was compared between groups, cases scored significantly worse for both the 4 second and 2 second subtests, with this difference persisting for the between pairs analysis (table 2). There was a non-significant trend for cases to score lower than controls for the map search subtest (table 2). In the telephone tasks, cases consistently took longer to perform the tests but the difference was not significant (table 2).

To further validate the results obtained, the subjects were matched by their NART scoring (IQ), reducing the number of matched pairs to 15. The results of this between group analysis are as follows: PASAT 4 second, $\mathrm{p}=0.009$; PASAT 2 second, $\mathrm{p}=0.067$; map search 2 minutes left, $\mathrm{p}=0.07$; map search 2 minutes right, $\mathrm{p}=0.03$. In addition, a multiple regression analysis was carried out so that all data could be used. A significant result was obtained for PASAT 4 second $(\mathrm{p}=0.0028)$.

Duration of atrial fibrillation, patient sex, and neuropsychological function

There was no correlation between duration of atrial fibrillation and patient age (women $r=0.22$, men $r=0.487$ ). Furthermore, there was no correlation between duration of atrial fibrillation and performance in any of the neuropsychological tests.

When the data were examined to determine the effect of duration of atrial fibrillation on outcome within the sexes there was no significant relation for male or female subjects.

\section{Discussion}

This was primarily a pilot study to explore our hypothesis that people with NVAF and no history of stroke or transient ischaemic attack are at increased risk of cognitive impairment as a result of silent cerebral infarction. Most of our subjects were able to complete the psychological test battery and likely difficulties could be predicted from the presence of visual and hearing impairment. Cases were well matched for the presence of cardiovascular symptoms and clinical signs although as expected a history of congestive heart failure was more frequent in the patients with NVAF.

Overall, the presence of atrial fibrillation was consistently associated with poorer performance on the test battery although significant differences between cases and controls existed only for the logical memory test and PASAT 2 second and 4 second tests. The difference on the PASAT was greater between cases and controls for the PASAT 4 second test than it was for the PASAT 2 second test. There is evidence that the PASAT 4 second test relies, to a significant degree, on memory function as well as attentional function. ${ }^{20}$ Hence the two tests which best discriminate cases with atrial fibrillation from controls-namely, the Wechsler logical memory and the PASAT 4 second test-both implicate the memory system. This suggests that atrial fibrillation has particular effects on memory and new learning, which is compatible with evidence that dementia in general is particularly linked to new learning and memory deficits, and that multi-infarct dementia in particular is linked to explicit as opposed to implicit memory. ${ }^{21}$

It is impossible to determine from our data whether some patients had coexistent dementia and cerebrovascular disease to account for their performance on the test battery. This study was designed to explore our hypothesis and determine the practicability of the test battery. We acknowledge that the numbers of patients studied are small and as such, subgroup analysis may be inappropriate. Nevertheless, we have shown a trend towards poorer performance on detailed neuropsychological testing in patients with NVAF and no history of stroke or transient ischaemic attack when compared with matched controls in sinus rhythm. The present study was a community based project and therefore imaging was not performed. In any future larger study, MRI would be essential to determine whether cognitive impairment in subjects with NVAF correlates with silent cerebral infarction.

We think that our hypothesis should be further examined in a prospective interventional study to determine whether antithrombotic therapy may protect against cognitive decline in patients at maximal risk of silent cerebral ischaemia.

1 Skoog I, Nilsoon L, Palmertz B, et al. A population based study of dementia in 85 year olds. $N$ Engl f Med 1993;328:153-8.

2 Kannel WB, Abbot RD, Savage DD, et al. Epidemiological features of chronic atrial fibrillation: the Framingham study. $N$ Engl F Med 1982;306:1018-22.

3 Evans JG. Risk factors for stroke in the elderly [MD dissertation]. Cambridge: University Of Cambridge, 1985.

4 O'Connell JE, Gray CS. Atrial fibrillation and stroke prevention in the community. Age Ageing 1996;25:307-9.

5 Wolf PA, Kannel WB, McGee DL, et al. Duration of atrial fibrillation and imminence of stroke; the Framingham fibrillation and imminence of

6 Peterson P, Boyson G, Gotfredsen J, et al. Placebo controlled randomised trial of warfarin and aspirin for prevention of thrombo-embolic complications in chronic atrial fibrillation:The Copenhagen AFASAK study. Lancet 1989; i: $175-9$.

7 Kempster PA, Gerraty RP, Gates PC. Asymptomatic cerebral infarction in patients with chronic atrial fibrillation. Stroke 1990;21:955-7.

8 EAFT Study Group. Silent brain infarction in nonheumatic atrial fibrillation. Neurology 1996;46:159-65.

9 Babikian VL, Wolfe N, Linn R, et al. Cognitive changes in Babikian VL, Wolfe $\mathrm{N}$, Linn R, et al. Cognitive changes in
patients with multiple cerebral infarcts. Stroke 1990;21: 1013-18.

10 Ferruci L, Guralnik JM, Salive ME, et al. Cognitive impairment and risk of stroke in the older population. $f$ Am Geriatr Soc 1996;44:237-41.

11 O'Connell JE, Gray CS. Atrial fibrillation and cognitive impairment. Lancet 1992;340:1169.

12 Folstein MF, Folstein SE, McHugh PR. Mini mental state-a practical method for grading the cognitive state of patients for the clinician. $\mathcal{F}$ Psychiatr Res 1975;12:189-98.

13 Nelson $H$. The national adult reading test (NART). Windsor: National Foundation for Educational Research,1982.

14 Wechsler DA. A standardised memory scale for clinical use. f Psychol 1945;19:87-95. 
15 Rey A. L'examen psychologique dans le cas d'encephalopathie traumatique. Archives de Psychologie 1941;28:286-340.

16 Wechsler D. The Wechsler adult intelligence scale (revised). London:The Psychological Corporation, 1986.

17 Gronwall DMA. Paced auditory serial addition task: a measure of recovery from concussion. Percept Mot Skills 1977;44:367-73.

18 Robertson IH, Ward A, Ridgeway V, et al. The test of everyday attention. Bury St Edmunds, UK: Thames Valley Test Company, 1994
19 Robertson IH, Ward A, Ridgeway V, et al. The structure of normal human attention:the test of everyday attention. normal human attention:the test of everyday attention.
fournal of the International Neuropsychology Society 1996;2: Fournal of

20 Deary IJ, Langan SJ, Hepburn DA, et al. Which abilities does the PASAT test? Personality and Individual Differences 1991;12:983-7.

21 Carlesimo GA, Fadda L, Marfia GA, et al. Explicit memory and repetition priming in dementia: evidence for a common basic mechanism underlying conscious and unconscious retrieval deficits. F Clin Exp Neuropsychol 1995;17:44-57 